\title{
E-Logic Trainer Kit: Development of an Electronic Educational Simulator and Quiz Kit for Logic Gate Combinational Circuit by Using Arduino as Application
}

\author{
https://doi.org/10.3991/ijoe.v15i14.11410 \\ Mohammad Zulkarnain O., Amar Faiz Z.A. ( $\left.{ }^{\bowtie}\right)$, Syahrul Hisham M. \\ Universiti Teknikal Malaysia Melaka, Melaka, Malaysia \\ amarfaiz@utem.edu.my \\ Nur Dalila K.A \\ Universiti Teknologi MARA, Johor, Malaysia \\ N. Ismail \\ Universiti Teknologi MARA, Selangor, Malaysia
}

\begin{abstract}
To supplement conventional teaching methods, use of new technology have recently being adapted in the current education system. Such examples are implementing simulators and quiz kits in a classroom session to assist teachers in providing standardized evaluation or practical and more direct examples of concepts that are being taught. Additionally, the well-known issue of attracting student interest in a so-called uninteresting conventional lecture may be solved by using this technological method. The objective of this works to provide methods on developing a prototype training kit (named as e-Logic trainer kit or e-LTK) which comprises of an electronic simulator and quiz assessment module to evaluate subject knowledge on logic gates. The e-LTK is developed by using Arduino Mega 2560 as the base microcontroller, equipped with keypad and display module as the user input/output interface. The quiz assessment module contained in the prototype also allows conversion of inputs by combinatorial logic circuits into output in the form of timing diagram. This equipment enables electrical engineering students to simulate several combinations of logic circuit, reinforcing the understanding of logic circuit operation. The effectiveness of using this prototype in educational settings have been evaluated through a survey on students and instructors at Faculty of Technology in Engineering (FTK) in Universiti Teknikal Malaysia Melaka (UTeM). Response has been positive, with $60 \%$ of the correspondence has shown positive feedbacks, indicating the usefulness of the prototype kit.
\end{abstract}

Keywords - Educational Kit, Digital Electronics, Electronic Quiz Board, simulator, Arduino. 


\section{Introduction}

Electronic industry has played a significant role in the global market due to its wide applications in variety of sectors. Rapid advancement in the electronic technology have been made to meet the demands and challenges of other sectors. Naturally, knowledge and understanding of the electronic will have an emphasis in the education system. In relation to this, the university has included the Digital Electronics (DE) as a core subject in electrical engineering course. Typically, this subject is perceived as difficult and its application to real world is not obvious in practice $[1,2]$. This may be due to the traditional approach of teaching where student passively received the information from the instructor or lecturer in classroom setting. Consider the expected key outcome of the DE subject as shown in Figure 1.

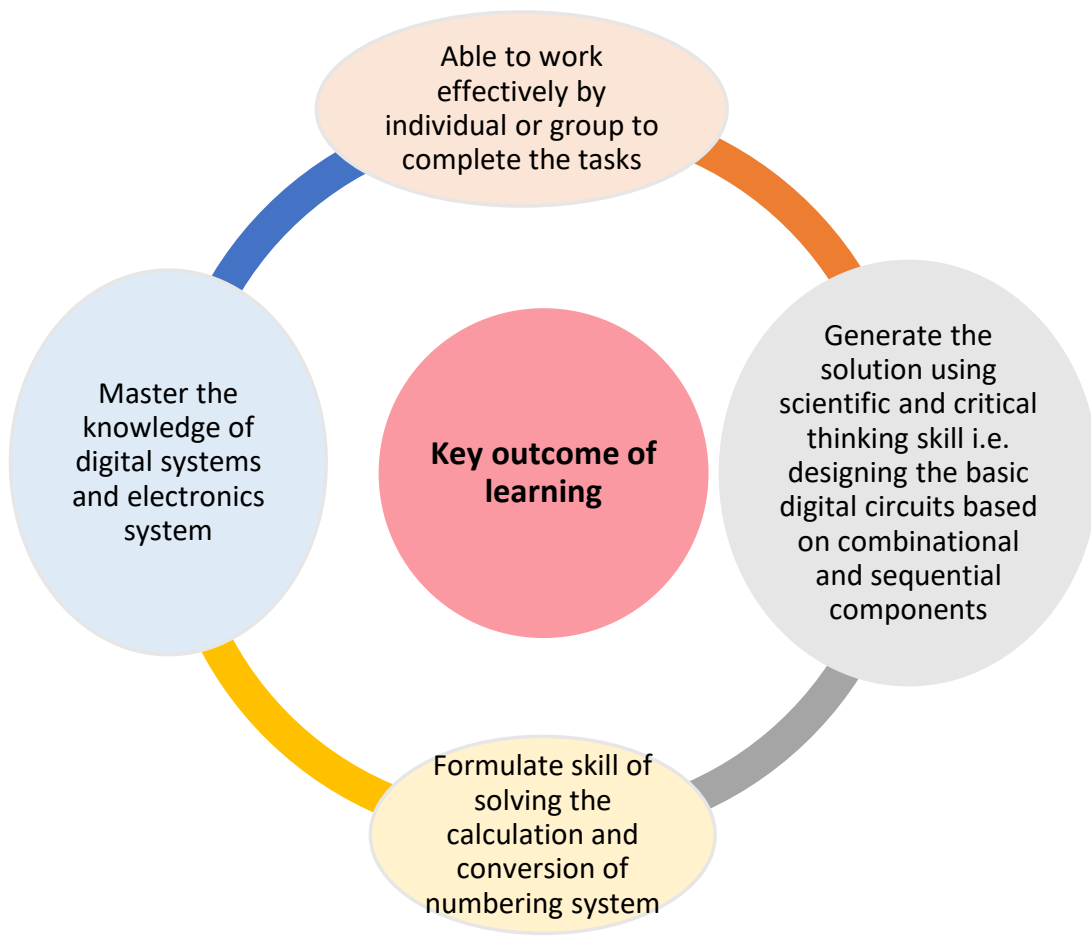

Fig. 1. Learning outcome of the proposed course

It is well-known that by applying learned concepts to real-world scenarios increases student interest and motivation for learning. Therefore, there is a need for the development of educational kit as supplementary aid system to link from concept to practical example [3, 4]. For example, simulators to show output formed when a digital circuit design was implemented by a student based on the combinational and sequential components learned in the course. Additional feature can be added on the kit to also help 
teacher and student to perform assessments through a quiz module, and in combination with simulator, can be implemented as a part of game-based learning system. This structure of learning [5] has an added advantage in terms of influencing the efficiency, selflearnability, memorability and satisfaction towards the course structure.

For the past ten years, researchers have demonstrated several innovations in teaching the DE course. To cater for different type of curriculum with similar basic DE knowledge such as computer science (CS) and electrical/computer engineering (ECE), the use of the simulator or hardware-based product may improve the teaching technique and student experience. Typically, the traditional method involves translating lecture content into calculations in paper-based design exercise, which involved doing truth table calculations or Karnaugh mapping for circuitry connection, for example. To support this teaching method, encouraging "learning while doing" approach in system design projects can help students to connect their learned concept from lectures to practical development [6-8]. In this case, educational tools can be implemented to improve student understanding. The summary of current educational tools developed for DE course are shown in Table 1. The existing literatures have demonstrated that various methodologies can be employed to improve learning experience with the use of hardware prototype, with simulator. However, several disadvantages need to be addressed such as fixed wired/not "plug and play", cost effectiveness and difficult development platform.

Table 1. Analysis of the literature for implemented innovations in DE course

\begin{tabular}{|l|l|}
\hline \multicolumn{1}{|c|}{ Author \& Year } & \multicolumn{1}{|c|}{ Paper Title/Features Summary and Tools/Methods } \\
\hline $\begin{array}{l}\text { L. A. Ajao, J. Agajo, A. O. } \\
\text { Ajao, T. Oke (2017) }\end{array}$ & $\begin{array}{l}\text { Development of a Low-Cost Digital Logic Training Module for Stu- } \\
\text { dents Laboratory Experiments [6] } \\
\text { The proposed training module comprised of fixed IC chip which are wired } \\
\text { with electronic components such as counter, decoder and display. Several } \\
\text { experiments to cater DE syllabus content including combinational logic } \\
\text { circuit aims to provide economical learning platform for students. }\end{array}$ \\
$\begin{array}{l}\text { Modeling and Design of Digital Electronic Systems [9] } \\
\text { The proposed learning technique using high level language namely HDL } \\
\text { (Hardware description Language) and FPGA (Field Programmable Gate } \\
\text { Arrays) which targets system-on-chip device prototyping. The advanced } \\
\text { method utilised may be considered for higher degree syllabus. }\end{array}$ \\
\hline $\begin{array}{l}\text { L Rakhmawati and A Firdha } \\
\text { (2015) }\end{array}$ & $\begin{array}{l}\text { The use of mobile learning application to the fundament of digital } \\
\text { electronics course [10] } \\
\text { Authors develop an Android based application of fundamental subjects in } \\
\text { DE course. Number of images and multimedia of logic simplification were } \\
\text { addressed in this application to be accessed by the teacher. }\end{array}$ \\
\hline $\begin{array}{l}\text { Experiment teaching of digital electronic technology using Multisim } \\
\mathbf{1 2 . 0} \text { [11] } \\
\text { Author demonstrated the use of Multisim 12.0 software to conduct simula- } \\
\text { tion of a basic logic function i.e. TTL inverter. This study merely consists } \\
\text { of virtual experiment without the use of actual hardware prototype in the } \\
\text { developed system. }\end{array}$ \\
\hline Qiu-xia Liu (2015)
\end{tabular}




\begin{tabular}{|l|l|}
\hline \multicolumn{1}{|c|}{ Author \& Year } & \multicolumn{1}{|c|}{ Paper Title/Features Summary and Tools/Methods } \\
\hline David Baneres (2015) & $\begin{array}{l}\text { Towards an Analytical Framework to Enhance Teaching Support in } \\
\text { Digital Systems Design Course [12] } \\
\text { Author develop a simulator via VerilUOC which contains a self-study ma- } \\
\text { terial to support teaching process. A web-based platform that has been de- } \\
\text { velop assist students to design digital circuit and further verify the out- } \\
\text { comes. Moreover, the support system for instructor allow them to analyti- } \\
\text { cally asses the students design submission in terms of quality and checks } \\
\text { for plagiarism. }\end{array}$ \\
\hline $\begin{array}{l}\text { Eduardo Garcia Breijo, Luis } \\
\text { Gil Sánchez, Javier Ibáñez } \\
\text { Civera (2014) } \\
\text { Charles Hacker (2009) }\end{array}$ & $\begin{array}{l}\text { Using Hardware Description Languages in a Basic Subject of Digital } \\
\text { Electronic [13] } \\
\text { Author adopted an integrated circuit as HDL as validation tool to under- } \\
\text { stand the concept of digital systems. } \\
\text { A Low Cost Student Constructed Digital Trainer [14] } \\
\text { A system developed to name as PortBuffer to replicate the function of dig- } \\
\text { ital trainer. It consists of interfacing board connected to the computer com- } \\
\text { plemented with PortDevice software to emulate the combinational con- } \\
\text { structed circuitry. }\end{array}$ \\
\hline $\begin{array}{l}\text { Lab at Home: Hardware Kits for a Digital Design Lab [15]Author pro- } \\
\text { pose the use of the take home kit consists of PLD (Altera) microprocessor } \\
\text { and electronic kits to learn basic digital design. Students are familiarized to } \\
\text { the kit, and taught the required precautions that should be taken to preserve } \\
\text { it in good condition. Due to the low cost of the kit components, students } \\
\text { can afford to pay for replacements in the event they break or lose them. }\end{array}$ \\
\hline
\end{tabular}

The motivation of pursuing this project is due to the confronted issues by students in electrical and electronic engineering to integrate the theoretical concept and practice in laboratory session. The traditional lecture-based type of teaching combines the theoretical class session followed by short quiz assessment and hands on laboratory session. The weakness that was observed is that the difference in student comprehension will affect the outcome of the laboratory session. The success of the lab activity will depend on the understanding of the students gained during the lecture. Therefore, it is crucial to gain student interest during the lecture session for better knowledge retainment. In line with this, the modern game-based teaching method has gained better support in modern education to retain student's focus.

In line with this view, the main novelty of the work presented in this paper is to support more interactive game-based teaching by proposing a low-cost trainer kit as a proof of concept to support the current teaching and learning process. Aims to be achieved in this paper as following:

- To propose an educational kit comprising of Multisim simulator and combinational arrangement of logic gates

- To convert the constructed logic gate into timing diagram

- To reflect and verify the effectiveness of implementation for classroom usage.

This training kit will be denoted as e-Logic Training Kit or e-LTK in short and is designed to complement the course material while assessing student understanding in DE subject. The training content is focused in combinational logic circuit development which involves constructing the required output from connecting variety of logic components. Using this kit, the student is required to construct the required logic gates com- 
bination on top of the trainer kit surface board. Once the connection has been completed, the microcontroller will process the received input and then produce the output in the form of high (1) or low (0) timing diagram. Using the trainer kit, student can quickly cross-evaluate the logic circuit design with the manual calculation, or even student can test themselves with variety of combination to check their understanding. Also, user can simulate the output of their own custom combination circuit design to check whether their circuit design is meeting the requirement.

\section{$2 \quad$ Methodology}

The block diagram of the proposed e-LTK consists of a microcontroller, inputs and outputs as illustrated in Fig.2. Specified criteria have been implemented by limiting the number of displayed input and output in the timing diagram into three and one respectively. For this purpose, a TFT LCD 2.4 is used to display the input and output of the timing diagram. Keypad $4 \times 4$ enables the user to choose the option from the selection menu such as simulation mode and assessment mode. Meanwhile the available logic gate for combination circuit comprises of five different types namely two-input AND, two-input OR, two-input XOR, three-input AND gate and a NOT gate. The functional modes that can be selected by user of the e-LTK can be described as following:

- Learning mode is enabled on LCD as default display menu selection. The user needs to press another button to select the other function. For simulation, user need to press " 1 " and the TFT LCD will display input timing diagram. So, user can do equivalent circuit connection on E-Logic Trainer Kit. The output of connection can be checked by pressing button " 4 ". When user had completed the simulation, user can press button "*" to returnto main menu.

- Assessment mode is the quiz mode which can be accessed by pressing button " 2 " at main menu. Then, for each question, the timing diagram for input labelled A, B, C will be displayed in green color. For displaying output of logic circuit connected by the user, which is labelled asY, it will also be displayed together in green color. Refering to the required input and output timing diagram, user need to do truth table and find the equivalent circuit. Timing diagram for answer will be displayed in blue color. If the green output diagram matches with the blue timing diagram, it shows that the logic gate combination is correct. This mode consists of nine question in increasing difficulty. On completion, student can press the "*" button to exit this mode and back to the main menu. 


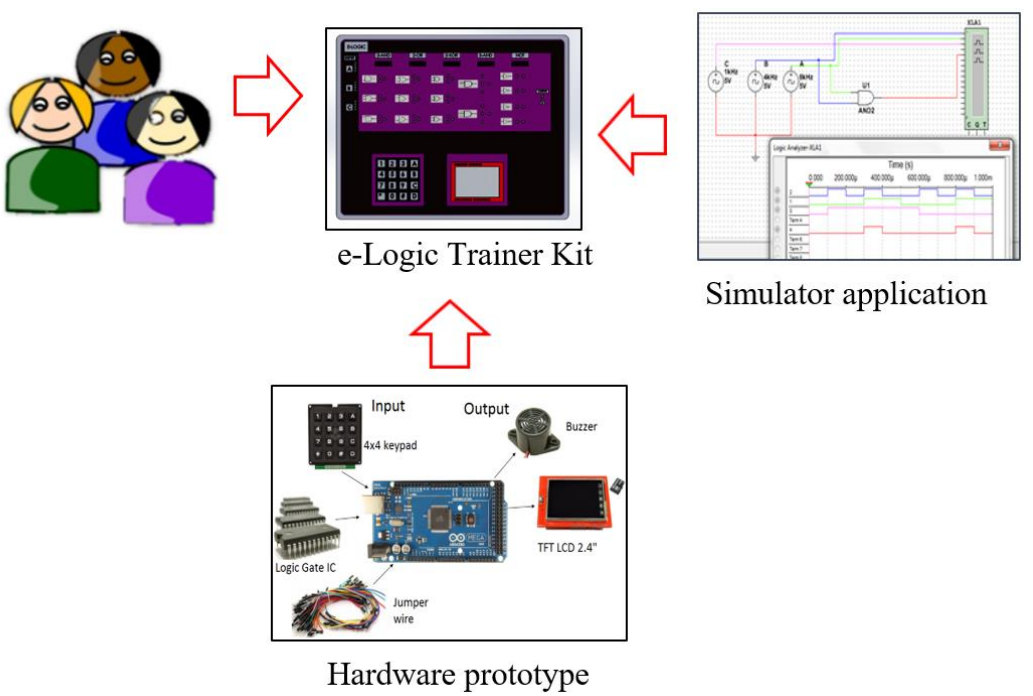

Fig. 2. Block diagram of the e-LTK

\section{Result and Discussion}

The e-LTK was tested and the result was compared with Multisim simulator via Logic Analayser software. Fig. 3 demostrated the comparisonoutcome for various cases of combinational logic gate configurations. The experiment was conducted by testing the possible configuration of all input and combinational logic gate. From observation, the E-LTK produces the same output with Multisim software. For example, in the basic case of two-input AND gate, which produces HIGH (1) output if all inputs are HIGH (1), both Multisim software and e-LTK prototype shows result in agreement with each other. Another case of comparison between hardware and software that uses two combinational logic gate comprises of two-input AND and NOT gate, the hardware also produce similar result with the simulator. In a more complex case of three inputs and five gates using triple two-input AND gates and double two-input OR gate, the prototype is able to match its output with the one simulated by Multisim. The positive match of several logic gate combination has shown that the prototype is successful in producing reliable result when given a combination of logic gates. 
Table 2. Comparison of results between Multisim simulator and hardware ptototype

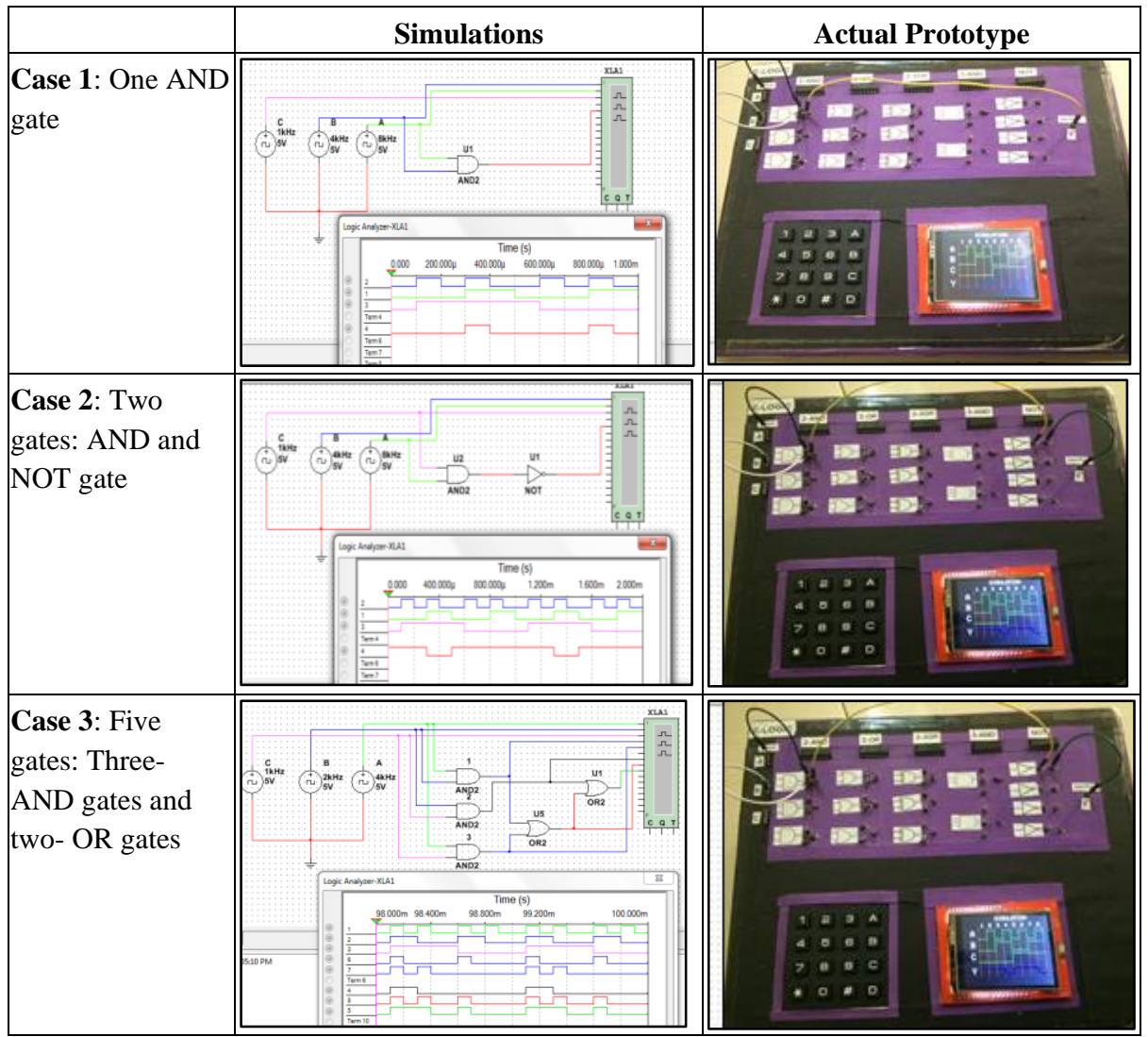

\section{$4 \quad$ Reflection and Evaluation of e-Logic Kit Implementation}

An investigation survey has been conducted to examine the e-LTK usability and suitability towards existing curriculum. In addition, the survey examines the student perceptions of the course and material retention between students in conventional laboratory as compared to the game-based laboratory. Therefore, ten (10) questions were developed and distributed among 50 respondents from students who sits for the electronic and electrical engineering related courses at FTK, UTeM. Table 3 demonstrates the details of the survey questions to the respondents using 5-Linkert scale type of questionnaire. 
Table 3. List of Questionaire

\begin{tabular}{|c|l|}
\hline Q1 & During Simulation, is it E-Logic Trainer Kit can give true answer to connection? \\
\hline Q2 & The question asked by E-Logic Trainer Kit is suitable for test student knowledge? \\
\hline Q3 & E-Logic Trainer Kit can be highly interactive activity during class session? \\
\hline Q4 & Student gained better understanding after answering the entire questions in E-Logic Trainer Kit? \\
\hline Q5 & E-Logic Trainer Kit can help student to improve their hands-on skill? \\
\hline Q6 & E-Logic Trainer Kit can be applied during lab session for subject Digital Electronic? \\
\hline Q7 & $\begin{array}{l}\text { Student prefer to learn Digital Electronic subject by using E-Logic Trainer Kit rather than in theo- } \\
\text { retically way. }\end{array}$ \\
\hline Q8 & This educational kit can help lecturer to teach easily student about logic gate response \\
\hline Q9 & Student can operate the quiz kit without any guidance of educator/teacher? \\
\hline Q10 & Do you think this E-Logic Trainer Kit can marketable in industry? \\
\hline
\end{tabular}

The impact of the implementation of the e-LTK was evaluated from the survey feedback. The feedback data is processed and graphed as in Fig. 3 for this study. The data analysis of survey conducted from questionnaire which distributed to respondent in the faculty. For question one (Q1), 52\% people strongly agree, $42 \%$ people agree and only $6 \%$ respondent expressed of neither agree nor disagree. This may cause by some of the respondents not able to successfully use the prototype, mainly unable to properly connect the jumper wire using the female pin at e-LTK. For question two (Q2), 60\% people strongly agree, $38 \%$ people agree and only $2 \%$ respondent neither agree nor disagree. For question three (Q3), $40 \%$ people strongly agree, $56 \%$ people agree and only $4 \%$ respondent neither agree nor disagree. Majority respondents agree with the Q3 because the student agreed that this kit able to attract student attention during class session. For question four (Q4), majority agreed that the quiz board helps to improve their knowledge on the design of combinational logic gate. For question five (Q5), similar to Q4, majority agreed with the statements. For question six (Q6), 12\% of the respondent disagree with the question because this trainer kit has a lack of proper instruction. Suggestion from respondent that the e-LTK need to include instruction book or instructional manual. For question seven (Q7), also has $6 \%$ in disagreement due to fact that the user/student also actually had to have basic understanding of the logic gate theory prior to using this kit. Thus, this kit is recommended to be used as a supplementary teaching material. For question eight (Q8), majority feedback shows positive response with this question. But has $2 \%$ respondent not sure either agree or disagree. For question nine (Q9), 3\% respondent disagreed with the statement. Similar to feedback for Q4, there is a need for guidance to operate this kit to make sure student got a correct answer when doing the quizzes. For question ten (Q10), all respondent is in agreement with this question because for respondent this kit can help them to more understand about logic gate. Overall, majority respondents that have tried e-LTK is giving positive feedback. Majority of the respondents agree that the e-LTK can improve their knowledge about logic gate. 


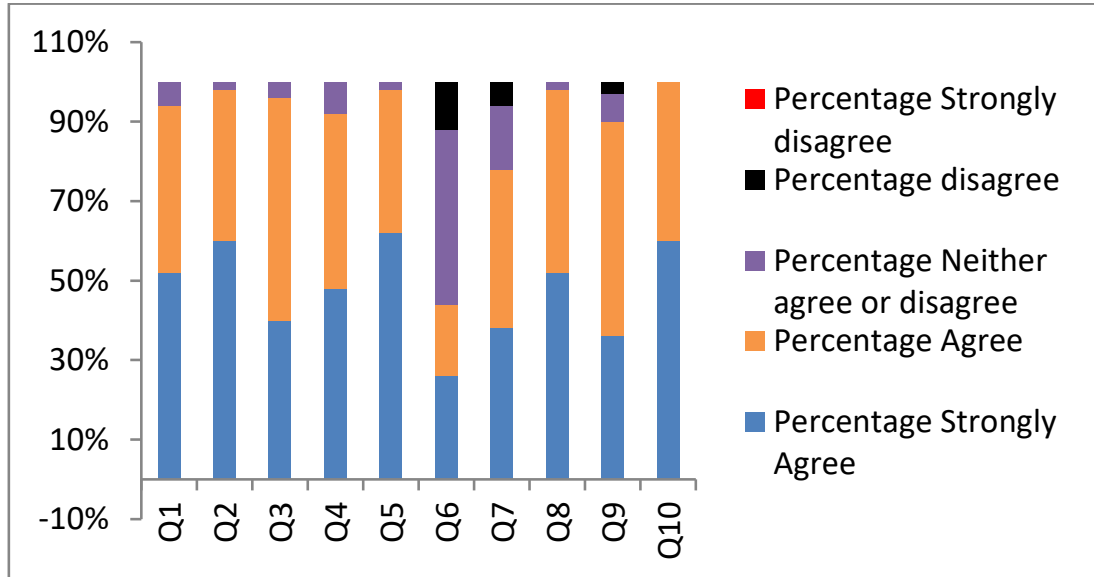

Fig. 3. Tabulation of data demonstrated the agreement/disagreement towards the use of the eLTK

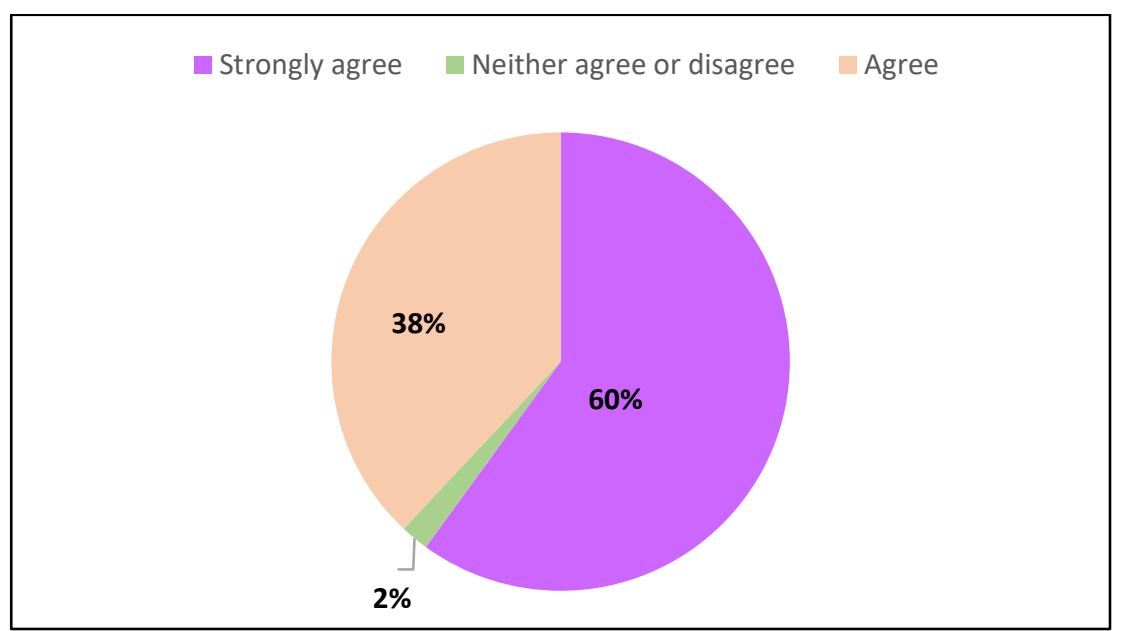

Fig. 4. Survey on the usage of the kit as interactive medium of teaching

Fig. 4 represents the overall data that has been collected from the respondent. $60 \%$ from respondents strongly agree and $38 \%$ agree that this kit can be used as an interactive medium of teaching. However, this is to be used as a supplementary material and recommended to be used during tutorial session. The $2 \%$ undetermined results derive from the respondent that prefers the traditional method of teaching using a white board.

\section{Conclusion}

This article has successfully proposed an innovative supplementary teaching method in Digital Electronic course. To meet this, the study had completed the development of 
a toolkit support the teaching of logic gate circuits in DE course. The developed prototype named as e-LTK comprises of the microcontroller that equipped with display module and several logic gate IC for enabling hardware connectivity. This tool enables students to verify the design of combinational logic gate comparable as traditional design method of using POS, SOP and Karnaugh-map for circuit simplification process. Feedback from survey has shown positive results from students using this toolkit. As a recommendation, this tool is to be used as supplementary material, preferably in a tutorial setting.

\section{Acknowledgement}

The authors would like to acknowledge and thank CRIM Universiti Teknikal Malaysia Melaka, and Universiti Teknologi MARA for collaborating and sponsoring this work.

\section{$7 \quad$ References}

[1] A., Alsadoon, P. W. C., Prasad, and A., Beg. "Using software simulators to enhance the learning of digital logic design for the information technology students", European Journal of Engineering Education, vol. 42, no. 5, pp. 533-546, 2017. https://doi.org/10.1080/030 $\underline{43797.2016 .1196344}$

[2] P.C., Prasad, A., Alsadoon, A., Beg, and A. Chan. "Incorporating simulation tools in the teaching of digital logic design", In IEEE International Conference on Control System, Computing and Engineering (ICCSCE 2014), 2014 Conference on IEEE, 2014, pp. 18-22. https://doi.org/10.1109/iccsce.2014.7072682

[3] M., Esteves, A., Pereira, N., Veiga, R., Vasco, and A. Veiga. "The use of new learning technologies in higher education classroom: a case study", in International Conference on Interactive Collaborative Learning, 2017 Conference on. Springer, pp. 499-506. https:// doi.org/10.3991/ijep.v8i2.8146

[4] M., Cornejo and B., O'Hara, "Moray: Bridging an Ancient Culture of Innovation with Emerging Pedagogies in Engineering", International Journal of Engineering Pedagogy, 2018, vol. 8, no. 4, pp 43-55. https://doi.org/10.3991/ijep.v8i4.8139

[5] M., Boeker, P., Andel, W., Vach, and A.,Frankenschmidt. "Game-based e-learning is more effective than a conventional instructional method: a randomized controlled trial with thirdyear medical students", PloS one, vol. 8, no. 12, p. e82328, 2013. https://doi.org/ 10.1371/journal.pone.0082328

[6] L.A, Ajao, J., Agajo, A.O., Ajao, J.T., Oke. "Development of a Low-Cost Digital Logic Training Module for Students Laboratory Experiments", Journal of Engineering and Technology, 2017, vol. 8, no. 1, pp 30-44.

[7] P., Bychkov, I., Zabrodina, M., Netesova, and C., Mapelli. "Game-Based Learning while Research Activities of Engineering Students", International Journal of Engineering Pedagogy,2018, vol. 8, no. 4, pp 153-161. https://doi.org/10.3991/ijep.v8i4.8126

[8] R., Wood, A., McGlashan, C., Moon, and W., Kim. "Engineering Education in an Integrated Setting", International Journal of Engineering Pedagogy, 2018, vol. 8, no. 3, pp. 17-27. 
[9] M., Cirstea. "Modeling and design of digital electronic systems", In International Conference on Development and Application Systems (DAS), 2016 Conference on. IEEE,2016,pp.189-194. https://doi.org/10.1109/daas.2016.7492596

[10] L., Rakhmawati and A., Firdha. "The use of mobile learning application to the fundament of digital electronics course", In IOP Conference Series: Materials Science and Engineering, 2018, vol. 296, no. 1, p. 012015. https://doi.org/10.1088/1757-899x/296/1/012015

[11] Qiu-xia, Liu. "Experiment teaching of digital electronic technology using Multisim 12.0", World Transactions on Engineering and Technology Education, 2014, vol. 12, no. 1, pp. 3742.

[12] D. Baneres, "Towards an analytical framework to enhance teaching support in digital systems design course", In 2015 Ninth International Conference on Complex, Intelligent, and Software Intensive Systems, 2015 Conference on. IEEE,2015, pp.148-155. https://doi.org/10.1109/CISIS.2015.20

[13] E.G., Breijo, L.G., Sánchez, and J.I., Civera. "Using hardware description languages in a basic subject of digital electronic: Adaptation to high academic performance group", In 2014 XI Tecnologias Aplicadas a la Ensenanza de la Electronica (Technologies Applied to Electronics Teaching) (TAEE), 2014 Conference on IEEE,2014, pp. 1-6. https://doi.org/10.11 09/TAEE.2014.6900163

[14] C., Hacker, "A low cost student constructed digital trainer", In 20th Annual Conference for the Australasian Association for Engineering Education, 2009, p. 369. https://doi.org/10.1109/TAEE.2014.6900163

[15] J. P., Oliver and F., Haim, "Lab at home: Hardware kits for a digital design lab", IEEE Transactions on Education, 2008, vol. 52, no. 1, pp. 46-51. https://doi.org/10.11 $\underline{\text { 09/TE.2008.917191 }}$

\section{Authors}

Mohammad Zulkarnain O. is with the Faculty of Electrical and Electronics Engineering Technology, Universiti Teknikal Malaysia, Melaka, 76100 Durian Tunggal, Melaka, Malaysia (b071410185@utem.edu.my)

Amar Faiz Z. A. is with the Faculty of Engineering Technology, Universiti Teknikal Malaysia, Melaka, 76100 Durian Tunggal, Melaka, Malaysia (amarfaiz@utem.edu.my)

Syahrul Hisham M. is with the Faculty of Electrical and Electronics Engineering Technology, Universiti Teknikal Malaysia, Melaka, 76100 Durian Tunggal, Melaka, Malaysia (syahrulhisham@utem.edu.my)

Nur Dalila K.A. is with the Department of System, Faculty of Electrical Engineering, Universiti Teknologi MARA, Johor, 81750 Masai, Malaysia (nurdalila306@uitm.edu.my)

N. Ismail. is with the Department of System, Faculty of Electrical Engineering, Universiti Teknologi MARA, Shah Alam, 40450 Shah Alam, Malaysia (nurlaila0583@uitm.edu.my)

Article submitted 2019-07-31. Resubmitted 2019-09-12. Final acceptance 2019-09-21. Final version published as submitted by the authors 